\title{
Construction of Hypoxia-Responsive VEGF Gene-Expression System Using Synthetic Biological Approach
}

\author{
Shinya MASUMOTO ${ }^{1}$, Akira $\mathrm{ITO}^{1}$, Akihiko $\mathrm{ONO}^{2}$, Tomonaga $\mathrm{SATO}^{1}$, Masaki YAMAGUCHI ${ }^{1}$, Yoshinori KAWABE ${ }^{1}$, and \\ Masamichi KAMIHIRA ${ }^{1,2^{*}}$ \\ ${ }^{1}$ Department of Chemical Engineering, Faculty of Engineering, Kyushu University, 744 Motooka, Nishi-ku, Fukuoka 819-0395, \\ Japan \\ ${ }^{2}$ Graduate School of Systems Life Sciences, Kyushu University, 744 Motooka, Nishi-ku, Fukuoka 819-0395, Japan
}

\begin{abstract}
Three-dimensional (3D) tissue construction from individual cells is an important process in regenerative medicine to enhance cell functions. In transplantation of tissue-engineered constructs, a limited oxygen/nutrient supply due to insufficient vascular network formation causes cell death. Thus, it is necessary to develop a system for inducing vascular networks into 3D tissue constructs under hypoxic conditions. In our previous study (Ono, A., et al., 2017), we developed a hypoxia-inducible transgene expression system in which a target gene can be expressed in response to hypoxic stress using hypoxia-responsive promoter RTP801 as a trigger, tTA transactivator as an amplifier, and oxygen-dependent degradation sequence as a noise canceler. In this study, to improve oxygen and nutritional limitation within engineered 3D tissue constructs, a hypoxia-responsive gene expression system for vascular endothelial growth factor (VEGF) was introduced into cells. We demonstrated that genetically engineered cells could regulate VEGF expression autonomously in an oxygen concentration-dependent manner. Using the genetically engineered cells, 3D tissue constructs were fabricated using a magnetic force-based tissue engineering technique (Ito, A., et al., 2005). The tissue constructs were transplanted into mice to evaluate the feasibility of the hypoxia-responsive VEGF gene expression system in vivo. The results indicated that the VEGF gene expression system is promising for the induction of vascular networks into 3D tissue constructs.
\end{abstract}

\section{Introduction}

In recent years, regenerative medicine has attracted attention for the purpose of functional recovery using functionalized cells as a solution for defects and dysfunction of tissues and organs. Three-dimensional (3D) tissue construction from individual cells is an important process in regenerative medicine to enhance cell functions. However, in transplantation of tissueengineered constructs, lack of oxygen/nutrition supply within the constructs due to "hypovascularity" causes a decrease in cell viability of the constructs. To address this problem, approaches such as artificial blood vessels and co-culture with vascular endothelial cells have been examined (Arai et al., 2018; Okudaira, et al., 2016). We previously succeeded in inducing angiogenesis of tissue constructs using VEGF expressing cells (Akiyama et al., 2010). VEGF binds to vascular endothelial growth factor receptor (VEGFR) on the surface of vascular endothelial cells and promotes cell division and migration. On the other hand, excessive expression of VEGF increases vascular membrane permeability (Lioret al. 2013), and hence regulation of VEGF expression is an important issue. Accordingly, we focused on hypoxia in 3D constructs and developed a hypoxia-responsive VEGF gene-expression system using synthetic biological methods (Figure 1). Hypoxia responsive promoter RTP801 regulates gene-expression in a hypoxic environment (Kim et al., 2009; Lee et al., 2004; Shoshani, et al., 2002). The RTP801 promoter activity is controlled by a hypoxia inducible factor (HIF) consisting of unstable HIF- $1 \alpha$ in the presence of oxygen and constitutively stable HIF-1 $\beta$. The stability of HIF- $1 \alpha$

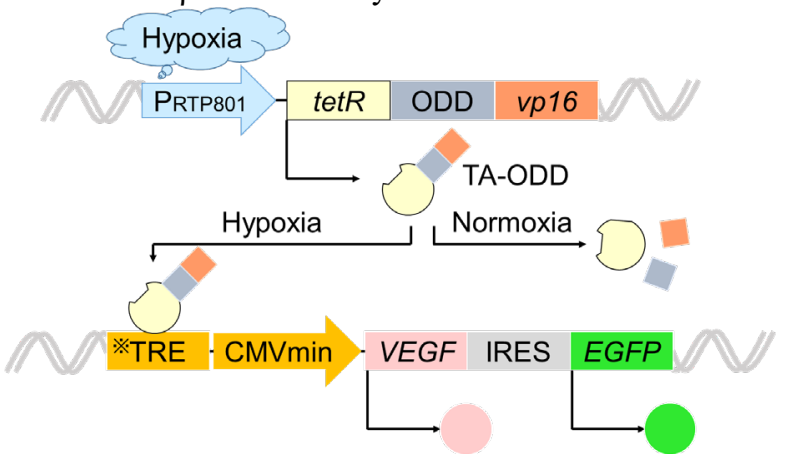

Figure 1. Gene construction of hypoxia-responsive VEGF gene expression system. $(※$ TetO region that recognizes TA-ODD protein contained in TRE sequence is repeated seven times)

\footnotetext{
Masamichi Kamihira: kamihira@chem-eng.kyushu-u.ac.jp
} 
is regulated by the ubiquitin-proteasome system, and central rule of the system is the oxygen-dependent degradation (ODD) domain (Ivan et al., 2001; Jaakkola, et al., 2001). The RTP801 promoter has a problem that the expression strength of downstream genes is low and it weakly works under normoxic conditions. In the hypoxiaresponsive VEGF gene-expression system, an artificial transcription activator TA-ODD comprising tetracyclineresponsive transactivator incorporated ODD domain is expressed under control of RTP801 promoter, and the expression of VEGF and EGFP genes is driven by TAODD. This system allows cells to control VEGF gene expression autonomously in response to hypoxia.

In this study, mouse myoblast $\mathrm{C} 2 \mathrm{C} 12$ cells equipped with the hypoxia-responsive VEGF gene expression system were prepared, and transgene expression of the cells was evaluated. Furthermore, 3D tissue constructs were fabricated using the genetically engineered $\mathrm{C} 2 \mathrm{C} 12$ cells. The tissue constructs were transplanted into mice to evaluate the feasibility of the hypoxia-responsive VEGF gene expression system in vivo.

\section{Experimental}

\subsection{Materials and method}

\subsubsection{Cells and cultures}

Mouse myoblast $\mathrm{C} 2 \mathrm{C} 12$ cells were grown in low-glucose Dulbecco's modified Eagle medium (DMEM) supplemented with $10 \%$ heat-inactivated fetal bovine serum (FBS), $0.1 \mathrm{mg} / \mathrm{ml}$ streptomycin sulfate, $100 \mathrm{U} / \mathrm{ml}$ potassium penicillin $\mathrm{G}, 3.7 \mathrm{mg} / \mathrm{ml}$ sodium hydrogen carbonate $\left(\mathrm{NaHCO}_{3}\right)$ and $20 \mathrm{mM}$ 2-[4-(2-hydroxyethyl)1-piperazinyl] ethanesulfonic acid (HEPES). 293FT cells were maintained on collagen coated dish in high-glucose DMEM supplemented with $10 \%$ FBS, $0.1 \mathrm{mg} / \mathrm{ml}$ streptomycin sulfate, $100 \mathrm{U} / \mathrm{ml}$ potassium penicillin $\mathrm{G}$, $3.7 \mathrm{mg} / \mathrm{ml} \mathrm{NaHCO} 3$ and $0.1 \mathrm{mM}$ non-essential amino acid (NEAA). For lentivirus vector production, DMEM supplemented with $20 \mathrm{mM}$ HEPES, $3.7 \mathrm{mg} / \mathrm{ml} \mathrm{NaHCO} 3$ and $77.6 \mathrm{mg} / \mathrm{ml}$ caffeine was mixed with normal medium for 293FT cells at ratio of 1:9. These cells were cultured at $37^{\circ} \mathrm{C}$ in a $5 \% \mathrm{CO}_{2}$ incubator.

\subsubsection{Production of lentiviral vector}

For lentiviral vector production, 293FT cells were seeded at $1.0 \times 10^{6}$ cells in $10 \mathrm{~cm}$ dish. At reaching $80 \%$ confluence, the cells were transfected with $3000 \mathrm{ng}$ pLP1, $7200 \mathrm{ng}$ pLP2, $4800 \mathrm{ng}$ pLP-VSV-G and $9000 \mathrm{ng}$ viral vector plasmids using Lipofectamine 2000 reagent. At $6 \mathrm{~h}$ post-transfection, medium was changed to caffeine containing medium. After $48 \mathrm{~h}$, the culture supernatant was filtered using a $0.45 \mu \mathrm{m}$ cellulose acetate filter, and virus vector solution was concentrated by ultracentrifugation at $60,000 \times \mathrm{g}$ for $2 \mathrm{~h}$.

\subsubsection{Measurement of viral titer}

The virus RNA titer was measured using Retrovirus titer set and One Step SYBR PrimeScript RT-PCR Kit according to the manufacturer's protocol.

One day after $\mathrm{C} 2 \mathrm{C} 12$ cells were seeded at $1.0 \times 10^{4}$ cells/well in a 6-well plate, $20 \mu 1$ of virus vector solution was added. After $20 \mathrm{~h}$, the medium was changed, and the cells were cultured for $2 \mathrm{~d}$. Then, green-fluorescent cell number was counted using a FACS device. Viral infectious titer was calculated from the number of infected cells, GFP positive rate, dilution ratio of virus, and liquid volume at the time of infection.

\subsubsection{Gene expression analysis for EGFP}

In gene expression analysis for screening and cloning, EGFP gene expression of cells was monitored. C2C12 cells infected with viral vector were cultured for $2 \mathrm{~d}$ and analysed using FACS. The fluorescent intensity threshold was set on wild type (WT) $\mathrm{C} 2 \mathrm{C} 12$ cells. The gene expression profiles of cells were evaluated by the fluorescent percentage of cells and median of the fluorescence intensity.

\subsubsection{Quantification of VEGF expression}

To quantify VEGF expression in cell culture supernatants, enzyme-linked immunosorbent assay (ELISA) was performed using Mouse VEGF-A platinum ELISA BMS619/2 according to manufacturer's protocol.

\subsubsection{Preparation of MCLs}

The magnetite $\left(\mathrm{Fe}_{3} \mathrm{O}_{4}\right.$; avarage particle size is $\left.10 \mathrm{~nm}\right)$ was purchased from Daiichikousyuha. The magnetic nanoparticles were dispersed by ultrasonic treatment for 1 h. For the preparation of magnetite cationic liposome (MCL), N-( $\alpha$-trimethylammonioacetyl)-didodecyl-Dglutamate chloride (TMAG), dilauroylphosphatidylcholine (DLPC) and dioleoylphosphatidyl-ethanol-amine (DOPE) in a molecular ratio of $1: 2: 2$ were dissolved in chloroform in a flask, and the solvent was evapolated to form a lipid film layer. After evapolation of the solvent, $10 \mathrm{mg} / \mathrm{ml}$ dispersed magnatic nanoparticles were added, and the flask was voltexed for $15 \mathrm{~min}$. Finally, sonication was applied for $1 \mathrm{~h}$ for dispersion and sterilization of the magnetic particles .

\subsubsection{Fabrication of cell sheets using Mag-TE}

For fabrication of cell sheets using a magnetic force-based tissue engineering (Mag-TE), C2C12 cells were cultured to harvest sufficient numbers of cells for magnetic labeling. Then $100 \mathrm{pg} / \mathrm{cell}$ MCLs were added to the cells, and cells were cultured for $4 \mathrm{~h}$. Subsequently, the cells were harvested and seeded at $1.2 \times 10^{6}$ cells in $500 \mu \mathrm{l}$ medium inside a silicone rubber tube, which was placed on the center of a $35 \mathrm{~mm}$ culture dish. Immediately thereafter, a cylindrical neodymium magnet (diameter; 30 $\mathrm{mm}$, height; $15 \mathrm{~mm}$ ) was placed under the dish to accumulate MCL-labeled cells on the dish surface and 
form a cell sheet. After $1 \mathrm{~h}$ culture, the silicone tube was removed and $1.5 \mathrm{ml}$ medium was added.

\subsubsection{Subcutaneous transplantation of cell sheets}

For transplantation experiments, female 4-5 weeks old KSN/Slc (Japan SLC) nude mice were used. Mice were anesthetized using isoflurane and a small incision was created in the dorsal skin. Cell sheets cultured for $1 \mathrm{~d}$ were rinsed 3 times with PBS and moved on thin films as a physical support using a magnet. Subsequently, the cell sheet-film was inserted subcutaneously into the dorsal skin and the film was removed, leaving the cell sheet. Thereafter, incision was closed using silk sutures. At $14 \mathrm{~d}$ post-implantation, mice were sacrificed and the tissues were harvested.

All animal experiments in this study were approved by the Ethics Committee for Animal Experiments of the Faculty of Engineering, Kyushu University (A30-247-0).

\subsubsection{Statistical analysis}

All date are expressed as means \pm SD. Statistical comparisons were evaluated using one-way analysis of variance (ANOVA), and any values of $\mathrm{P}<0.05$ were considered significantly different.

\subsection{Results}

The hypoxia-responsive VEGF gene expression system (Figure 1) was transduced into $\mathrm{C} 2 \mathrm{C} 12$ cells by lentiviral vector. To generate variation in gene expression range, cells were infected using two different multiplicity of infection (MOI), MOI2 and MOI30. Using the limiting dilution method, 48 cell clones were obtained from MOI2 and MOI30 cells. In order to select clones that renponded strictly to the hypoxic environment from transduced cells, the gene expression of EGFP reporter was analyzed. Clone MOI30 \#5 was selected because the cells exhibited the most difference in EGFP fluorescent percentage of cells between hypoxic culture $\left(\mathrm{O}_{2}: 1 \%\right)$ and normoxic culture $\left(\mathrm{O}_{2}: 19 \%\right)$ (Figure 2). Clone MOI30 \#8 was also selected because the cells exhibited the most difference in EGFP mean fluorescent intensity (Figure 3).

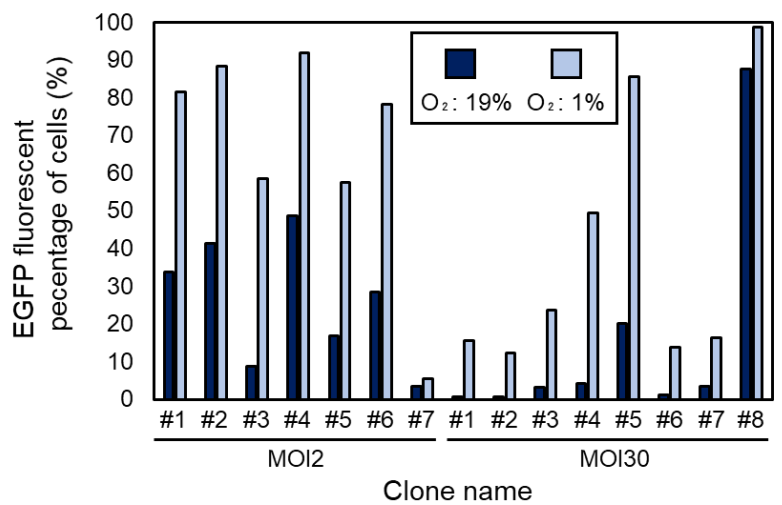

Figure 2. EGFP fluorescent percentage of clones

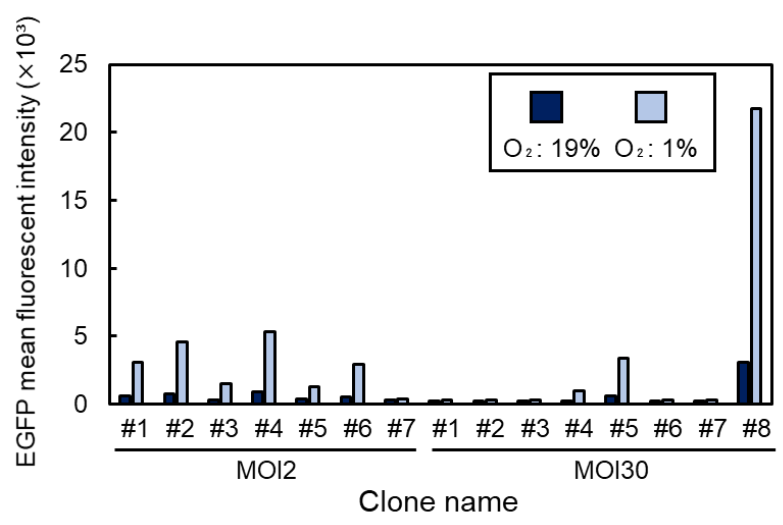

Figure 3. EGFP mean fluorescent intensity of clones

VEGF production in the culture supernatants for the selected two clones was quantified using ELISA (Table 1). VEGF production of both clones was significantly enhanced under hypoxic conditions. Especially, the level of VEGF production for MOI30 \#5 cultured under normoxic conditions was almost equivalent to $\mathrm{C} 2 \mathrm{C} 12 \mathrm{WT}$ cells, indicating strict hypoxia responsiveness. Therefore, clone MOI30 \#5 was used for subsequent cell sheet experiments and in vivo assay.

Table 1. VEGF gene quantification of clones

\begin{tabular}{|l|l|l|}
\hline \multirow{2}{*}{ Cell } & \multicolumn{2}{|l|}{ VEGF expression (ng/ml) } \\
\cline { 2 - 3 } & $\mathbf{O}_{\mathbf{2}} \mathbf{1 9 \%}$ & $\mathbf{O}_{\mathbf{2}} \mathbf{1 \%}$ \\
\hline $\mathrm{C} 2 \mathrm{C} 12 \mathrm{WT}$ cells & $3.31 \pm 0.05$ & $3.88 \pm 0.46$ \\
\hline $\mathrm{MOI} 30 \# 5$ & $3.77 \pm 0.02$ & $14.9 \pm 2.06$ \\
\hline MOI30 \#8 & $26.2 \pm 0.19$ & $39.8 \pm 0.54$ \\
\hline
\end{tabular}

Cell sheets using C2C12 WT, MOI30 \#5 and constitutively VEGF gene expressing clone CMV \#2 were prepared using Mag-TE method, and VEGF production was quantified by ELISA. As the result, VEGF production was observed for cell sheets using MOI30 \#5 and CMV $\# 2$, suggesting that VEGF production was induced in response to hypoxic environment inside the tissue construct for MOI30 \#5.

Table 2. VEGF gene quantification of cell sheets

\begin{tabular}{|l|l|}
\hline $\begin{array}{l}\text { Cell sheet } \\
\left.\mathbf{( 1 . 2} \times \mathbf{1 0}^{\mathbf{6}} \text { cells/sheet }\right)\end{array}$ & $\begin{array}{l}\text { VEGF expression } \\
(\mathbf{n g} / \mathbf{m l})\end{array}$ \\
\hline C2C12 WT cells & $0.481 \pm 0.533$ \\
\hline MOI30 \#5 & $95.5 \pm 8.49$ \\
\hline CMV $\# 2$ & $187 \pm 18.4$ \\
\hline
\end{tabular}

Cell sheets (C2C12 WT, MOI30 \#5 and CMV \#2) were implanted subcutaneously in mice and incubated for $14 \mathrm{~d}$. The tissues were removed from the mice using biopsy punch and observed by hematoxylin-Eosin (HE) staining (Fig. 4A, 4B and 4C). The cell sheets containing magnetic nanoparticles as detected in black dots. Furthermore, microvessel-like structures were observed around MOI30 \#5 and CMV \#2 cell sheets (Fig. 4B and 4C). 

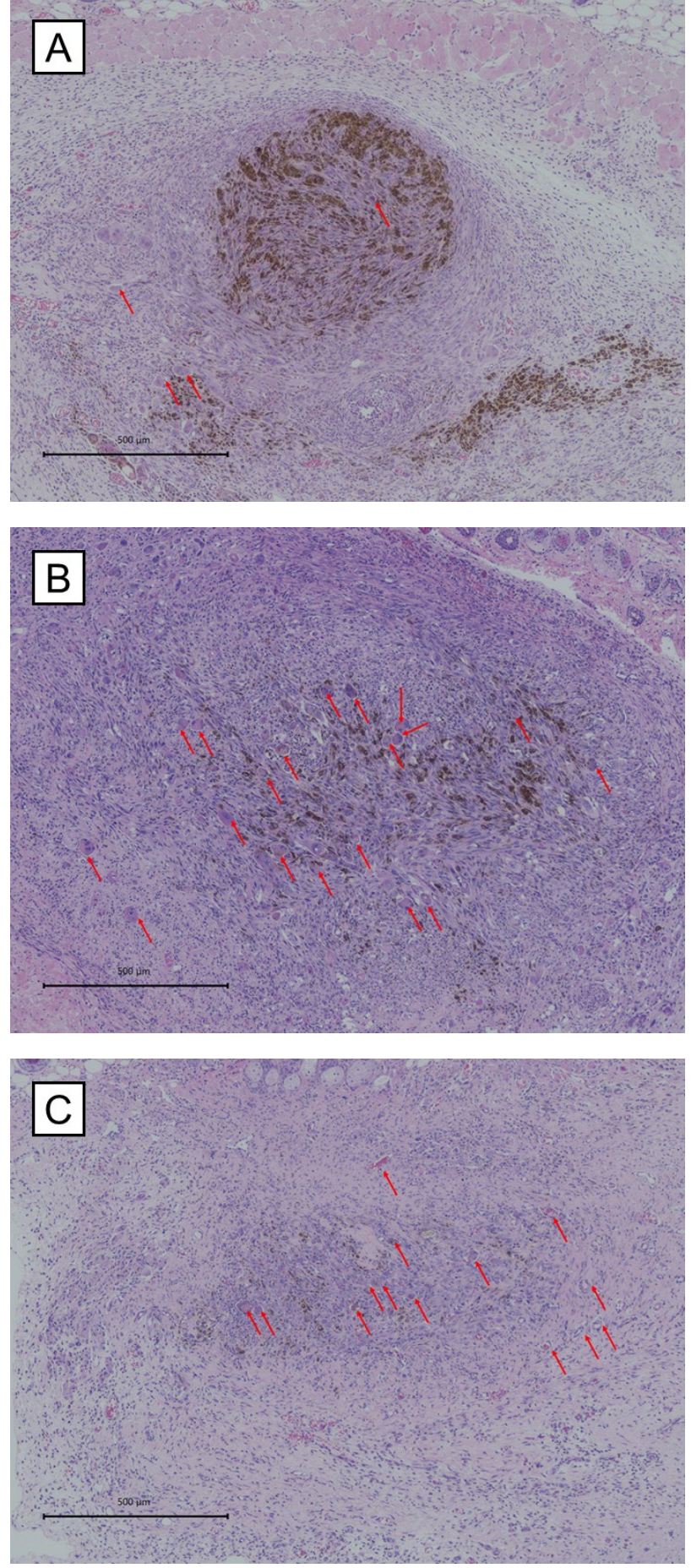

Figure 4. HE staining of $\mathrm{C} 2 \mathrm{C} 12 \mathrm{WT}$ cell sheets (A), MOI30 \#5 cell sheets (B) and CMV \#2 cell sheets (C)

\section{Discussion}

In this study, we created genetically engineered cells equipped with hypoxia-responsive gene expression of angiogenesis factor VEGF. Microvessel-like structures were induced in mouse body by transplanting cell sheet comprising the genetically engineered cells. Angiogenesis in response to hypoxia is often observed for tumor tissues. In general, local hypoxic environment is caused inside tumor tissues because angiogenesis cannot keep up with the growth rate of cancer cells. Further, HIF is often activated and promote angiogenesis in tumor tissues, causing cancer metastasis/invasion, and treatment resistance (Semenza, 2012; Ji et al., 2010; Gardner et al., 2001; Harada, 2011). By applying the VEGF gene expression system developed in this study to transplanted tissues, various advantages can be obtained. Autonomous angiogenesis allows the creation of microvascular networks that cannot be produced using artificial devices. In addition, by expressing an angiogenesis factor specifically under hypoxia, an ideal vascular network for transplanted tissue will be created. On the other hand, there are some issues to be considered. One of the problems is the risk of tumorigenesis of transplanted tissues due to genetic modification. The use of human artificial chromosomes (HACs) has been proposed as a method for stably introducing gene expression systems into cells while reducing the risk of tumorigenesis (Kuroiwa et al., 2000). Secondly, the original angiogenic system is more complex, and expression of factors such as angiopoetin1, may be essential for the creation of a robust vascular network (Thurston, 2002; Brudno et al., 2013).

This VEGF gene expression system provides the first platform for the creation of an autonomous vascular network by the tissue itself. Furthermore, we will analyze the expression behavior of VEGF gene in the cell sheets and the presence of endothelial cells to confirm the usefulness of this hypoxia-responsive VEGF gene expression system in regenerative medicine.

\section{Acknowledgements}

The authors thank Mr. M. Tatsumi, Narabyouri Research Corporation for preparation of the tissue sections.

\section{References}

Akiyama, H., A. Ito, Y. Kawabe and M. Kamihira; "Genetically Engineered Angiogenic Cell Sheets Using Magnetic Force-Based Gene Delivery and Tissue Fabrication Techniques," Biomaterials, 31, 1251-1259 (2010)

Arai, K., D. Murata, A. R. Verissimo, Y. Mukae, M. Itoh, A. Nakamura, S. Morita and K. Nakayama; "Fabrication of Scaffold-Free Tubular Cardiac Constructs Using a Bio3D Printer," PLoS One, 13, e0209162 (2018)

Brudno, Y., A. B. Ennett-Shepard, R. R. Chen, M. Aizenberg and D. J Mooney; "Enhancing Microvascular Formation and Vessel Maturation through Temporal Control over Multiple Pro-Angiogenic and ProMaturation Factors," Biomaterials, 34, 9201-9209 (2013)

Gardner, L. B., Q. Li, M. S. Park, W. M. Flanagan, G. L. Semenza and C. V. Dang; "Hypoxia Inhibits G1/S Transition through Regulation of p27 Expression," J. Biol. Chem., 276, 7919-7926 (2001) 
Harada, H.; "How Can We Overcome Tumor Hypoxia in Radiation Therapy?," J. Radiat. Res., 52, 545-556 (2011)

Ito, A., M. Shinkai, H. Honda and T. Kobayashi; "Medical Application of Functionalized Magnetic Nanoparticles," J. Biosci. Bioeng., 100, 1-11 (2005)

Ivan, M., K. Kondo, H. Yang, W. Kim, J. Valiando, M. Ohh, A. Salic, J. M. Asara, W. S. Lane and W. G. Kaelin, Jr.; "HIF $\alpha$ Targeted for VHL-Mediated Destruction by Proline Hydroxylation: Implications for $\mathrm{O}_{2}$ Sensing," Science, 292, 464-68 (2001)

Jaakkola, P., D. R. Mole, Y. M. Tian, M. I. Wilson, J. Gielbert, S. J. Gaskell, A. von Kriegsheim, H. F. Hebestreit, M. Mukherji, C. J. Schofield, P. H. Maxwell, C. W. Pugh and P. J. Ratcliffe; "Targeting of HIF- $\alpha$ to the von Hippel-Lindau Ubiquitylation Complex by $\mathrm{O}_{2-}$ Regulated Prolyl Hydroxylation," Science, 292, 468-472 (2001)

Ji, Z., H. Long, Y. Hu, X. Qui, X. Chen, Z. Li, D. Fan, B. $\mathrm{Ma}$ and Q. Fan; "Expression of MDR1, HIF-1 $\alpha$ and MRP1 in Sacral Chordoma and Chordoma Cell Line CM319," J. Exp. Clin. Cancer Res., 29, 158 (2010)

Kim, H. A., R. I. Mahato, and M. Lee; "Hypoxia-Specific Gene Expression for Ischemic Disease Gene Therapy," Adv. Drug Deliv. Rev., 61, 614-622 (2009)

Kuroiwa, Y., K. Tomizuka, T. Shinohara, Y. Kazuki, H. Yoshida, A. Ohguma, T. Yamamoto, S. Tanaka, M. Oshimura and I. Ishida; "Manipulation of Human Minichromosomes to Carry Greater than Megabase-Sized Chromosome Inserts," Nat. Biontechnol., 18, 1086-1090 (2000)

Lee, M., M. Bikram, S. Oh, D. A. Bull, and S. W. Kim; "Sp1-Dependent Regulation of the RTP801 Promoter and
Its Application to Hypoxia-Inducible VEGF Plasmid for Ischemic Disease," Pharm. Res., 21, 736-741 (2004)

Okudaira, T., N. Amimoto, H. Mizumoto, and T. Kajiwara; "Formation of Three-Dimensional Hepatic Tissue by the Bottom-up Method Using Spheroids," $J$. Biosci. Bioeng., 122, 213-218 (2016)

Ono, A., A. Ito, T. Sato, M. Yamaguchi, T. Suzuki, Y. Kawabe and M. Kamihira; "Hypoxia-Responsive Transgene Expression System Using RTP801 Promoter and Synthetic Transactivator Fused with OxygenDependent Degradation Domain," J. Biosci. Bioeng., 124, 115-124 (2017)

Semenza, G. L.; "Molecular Mechanisms Mediating Metastasis of Hypoxic Breast Cancer Cells," Trends Mol. Med., 18, 534-543 (2012)

Shoshani, T., A. Fearman, I. Mett, E. Zelin, T. Tenne, S. Gorodin, Y. Moshel, S. Elbaz, A. Budanov, A. Chajut, H. Kalinski, I. Kamer, A. Rozen, O. Mor, E. Keshet, D. Leshkowitz, P. Einat, R. Skaliter and E. Feinstein; "Identification of a Novel Hypoxia-Inducible Factor 1Responsive Gene, RTP801, Involved in Apoptosis," Mol. Cell. Biol., 22, 2283-2293 (2002)

Thurston, G.; "Complementary Actions of VEGF and Angiopoietin-1 on Blood Vessel Growth and Leakage," $J$. Anat., 200, 575-580 (2002)

Zangi, L., K. O. Lui, A. von Gise, Q. Ma, W. Ebina, L. M. Ptaszek, D. Später, H. Xu, M. Tabebordbar, R. Gorbatov, B. Sena, M. Nahrendorf, D. M. Briscoe, R. A. Li, A. J. Wagers, D. J. Rossi, W. T. Pu and K. R. Chien; "Modified mRNA Directs the Fate of Heart Progenitor Cells and Induces Vascular Regeneration after Myocardial Infarction," Nat. Biotechnol., 31, 898-907 (2013) 